\title{
(c) \\ AZAR E INTUICIÓN: EL TEATRO DE ESTADOS EN LA PRÁCTICA ACTORAL RIOPLATENSE
}

\author{
TO SENSE THE UNEXPECTED: THE THEATER OF STATES IN \\ RIOPLATENSE ACTING
}

Eugenio Schcolnicov

CONICET-Universidad de Buenos Aires

(eugeniobuzon@gmail.com)

https:/orcid.org/0000-0002-2078-6114

(2)

DOI: https://doi.org/10.32621/acotaciones.2020.44.02

ISSN 2444-3948

Resumen: El siguiente trabajo se propone estudiar el nacimiento y el desarrollo del teatro de estados, uno de los paradigmas más productivos en la historia teatral de Argentina. Desde nuestra perspectiva, la práctica actoral del teatro de estados define una categoría teórica que permite pensar de forma simultánea una modalidad de producción escénica, una poética de actuación y un sistema organizativo del trabajo en la dirección teatral. A nivel geográfico y territorial, las formas de producción presentes en el teatro de estados nacen de las exploraciones escénicas desarrolladas por un conjunto de actores y directores en el campo teatral de Buenos Aires desde fines de la década del '70. Para realizar el estudio, partiremos de los fundamentos teóricos y metodológicos desarrollados por la disciplina de la Poética Comparada (Dubatti, 2012) y de la comprensión en torno al trabajo del actor desarrollada por la Filosofía del Teatro (Dubatti, 2010). El trabajo se inicia con un breve recorrido histórico en torno al desarrollo del teatro de estados y sus principales referentes, para luego reconocer las características que definen a esta práctica 
como un fenómeno de liminalidad teatral. Por último, analizaremos un ejemplo específico del teatro de estados a partir del estudio del espectáculo Variaciones Meyerhold, de Eduardo Pavlovsky.

Palabras Clave: Teatro de estados, Estudios Teatrales, Historia de la actuación, Historia de la Dirección Teatral, Teatro argentino, Liminalidad.

Abstract: This paper intends to study the birth and development of the theater of states, one of the most productive paradigms in argentinian theater. From our point of view, the expression theater of states defines a theoretical category that makes thinkable a mode of stage production, a poetic of acting and an organizational system of work in theatrical direction. The forms of production present in the theater of states are born from the scenic explorations developed by a group of actors and directors began their work in the Buenos Aires' theater field in the late '70s. Our work takes as its theorical starting points the discipline of Comparative Poetics (Dubatti, 2012) and the understanding around the work of the actor developed by the Theater Philosophy (Dubatti, 2010). The paper begins with a brief historical journey around the development of the «theater of states» and its main figures, and then attempts a recognition of the characteristics that define this theatrical practice as a phenomenon of liminality. Finally, we will analyze a specific example of the "theater of states" from the study of the show Variaciones Mayerhold, by Eduardo Pavlovsky.

Key Words: «Theater of states», Theater Studies, Latinamerican Theatre, History of acting, Theater Directing History.

Sumario: 1, Introducción. 2. Orígenes. 3 Continuidad y resonancias. 4. Teatro de estados y liminalidad. 5. Variaciones Meyehold. 6 Conclusiones. 7. Obras citadas.

Copyright: (C) 2020. Este es un artículo abierto distribuido bajo los términos de una licencia de uso y distribución Creative Commons 4.0 Internacional (CC BY 4.0) 
Eugenio SchColnicov es actor, docente e investigador teatral. Becario doctoral del CONICET. Formado en la carrera de Artes en la Universidad de Buenos Aires y becario en el «Área de investigación en Ciencias del Arte» del Centro Cultural de la Cooperación. Participa como investigador en el proyecto Ubacyt «Historia del Teatro Universal y Teatro Comparado: origen y desarrollo del teatro de la vanguardia histórica», coordinado por Jorge Dubatti. Ha colaborado en diversas publicaciones especializadas en teatro. 



\section{INTRODUCCIÓN}

El desarrollo del teatro de posdictadura en la Argentina posibilitó, entre un amplio conjunto de novedades, el despliegue de una nueva metodología de creación y de trabajo que pone el acento en el cuerpo del actor y su fuerza expresiva: se trata del teatro de estados, categoría que permite pensar de forma simultánea una modalidad de producción escénica, una poética de actuación y un sistema organizativo del trabajo de dirección teatral. Este conjunto de particularidades distintivas permite entrever en esta forma de producción uno de los paradigmas más fecundos en la historia escénica de Buenos Aires. A nivel geográfico y territorial, las formas de producción presentes en el teatro de estados asumen un origen rioplatense, en tanto son el resultado de las exploraciones escénicas llevadas adelante por una serie de actores y directores en el campo teatral de Buenos Aires desde fines de la década del setenta. No se trata, sin embargo, de un dispositivo monolítico y articulado de procedimientos, metodologías o de marcas formales y temáticas que se reiteran de manera uniforme en diversos creadores, sino más bien de una manera de aproximarse al oficio actoral y de un tipo particular de pensamiento sobre lo que constituye su naturaleza. En este sentido, la heterogeneidad formal que se advierte entre los precursores del teatro de estados, y que serán analizados en este trabajo, resulta un factor clave para pensar la amplitud del concepto.

En sus diversas manifestaciones y modalidades, el conjunto de creadores comprendidos bajo la categoría del teatro de estados afirma la voluntad común de repensar el cuerpo del actor en la instancia de producción de poíesio, a partir de la fractura del universo referencial constituido por la ficción dramática y sus límites. Teatro que nace del cuerpo del actor puesto en tensión, de su voluntad expresiva anterior a toda organización de sentido, la categoría estudiada ha consolidado también una clara filosofía de la praxis: a partir de sus concepciones teóricas y de la observación de sus manifestaciones, la Filosofía del Teatro elabora su aparato conceptual en torno al teatro como acontecimiento y a la primacía del cuerpo del actor en la actividad escénica. Por lo tanto, resulta central, a la hora de pensar el desarrollo teatral argentino y latinoamericano en las últimas décadas, aventurarse en el reconocimiento de esta singular manera de pensar el trabajo del actor, observando las formas variables en las que se manifiesta. En la recurrencia sobre ciertos tópicos en torno 
a la problemática y a la naturaleza de la actuación, la poética del teatro de estados va delineando una genealogía silenciosa y a la vez constante.

Para considerar el desarrollo del fenómeno analizado, trabajaremos a partir de los fundamentos teóricos y metodológicos desarrollados por la disciplina de la Poética Comparada (Dubatti, 2012) y de la comprensión del trabajo del actor elaborada por la Filosofía del Teatro (Dubatti, 2010). Partiremos de un breve recorrido histórico en torno al nacimiento y consolidación del teatro de estados, caracterizando a sus principales referentes, para luego reconocer las particularidades que definen a esta práctica como un fenómeno de liminalidad teatral (Dubatti, 2016). Durante este recorrido, nos detendremos en las reflexiones teóricas elaboradas por Eduardo Pavlovsky, Alberto Ure y Ricardo Bartis, tres creadores centrales para pensar la evolución del teatro de estados como paradigma de producción teatral. Por último, analizaremos un ejemplo específico que revela una de las formas posibles de esta categoría a partir del espectáculo Variaciones Meyerhold, estrenado por Eduardo Pavlovsky en el año 2005.

\section{Orígenes}

La definición inicial del teatro de estados le pertenece al actor, psicoanalista y dramaturgo argentino Eduardo Pavlovsky, quien acuña este término para dar cuenta de una nueva forma de aproximarse a la producción teatral en su regreso a la Argentina luego de su exilio en 1978. Esta categoría, tal como la entiende Pavlovsky, condensa una metodología de improvisación y de creación escénica que integra aportes teóricos múltiples y variados: desde los principios filosóficos elaborados por Gilles Deleuze y Félix Guattari y la teoría del psicodrama -a partir de las premisas teóricas de Jacob Levy Moreno y de los aportes posteriores del propio Pavlovsky junto a Hernán Kesselman-, hasta la noción de accidente desarrollada por el pintor Francis Bacon. En la conceptualización del teatro de estados se advierten también las premisas que definen el teatro pobre de Jerzy Grotowski, en la valorización del cuerpo del actor como agente productor de sentido y elemento central del acontecimiento teatral. Acerca de la influencia del director polaco, dice Pavlovsky (2001): «Grotowski cambia mi concepción sobre el ser del actor: no se trata de transformarse en otro sino en ser más uno mismo. (...) asumir un 
personaje no es enmascararse sino desenmascararse, exponerse, quedar desprovisto» (pág. 73). La presencia de Grotowski se advierte también en la cualidad autopoiética que Pavlovsky reconoce en el proceso de construcción escénica, a través de una concepción de la actuación en donde los procesos internos desplegados por el actor en el ejercicio de la improvisación dictan el desarrollo del relato escénico, en oposición a un modelo de teatro conceptual, que parte de esquemas racionales y a priori para organizar la producción de sentido.

El andamiaje conceptual elaborado por Gilles Deleuze junto a Félix Guattari le permite a Pavlovsky definir los postulados de una estética de la multiplicidad, espacio de emergencia del teatro de estados. En ella se perfilan los procedimientos y las operaciones formales de «un teatro «no representacional», sostenido por una narrativa de intensidades y de condensaciones emocionales, que se dispara fragmentariamente hacia múltiples direcciones y que cuestiona la coherencia y la linealidad del relato tradicional (Dubatti, 2004). La estética de la multiplicidad concibe una dramaturgia que nace en el cuerpo del actor, a partir de una conciencia rítmica y musical de las acciones físico-verbales desplegadas, violentando el principio de causalidad que caracteriza al modelo de actuación stanislavskiano. Los elementos centrales de los que se sirve el actor para su trabajo en la escena no parten de un esquema psicologista, sino que descubren en el gesto, las velocidades, el ritmo, las temperaturas y las energías de su cuerpo la materia prima desde la cual fundar el acontecimiento teatral. Por su parte, el enlace asociativo que despliega el actor en escena, sin hallarse sujeto a la normatividad de sentido que impone el texto, posibilita pensar la práctica actoral a partir del concepto de rizoma. Frente a la lógica binaria, que desde la perspectiva deleuziana inunda el psicoanálisis, la lingüística y la historia del pensamiento a partir de la figura del árbol-raíz, la figura del rizoma, dispuesta en múltiples operaciones estéticas y cognitivas, conecta puntos diversos en donde «cada rasgo no remite necesariamente a un rasgo lingüístico: eslabones semióticos de cualquier naturaleza se conectan en él con formas de codificación muy diversas, eslabones biológicos, políticos, económicos, etc..., poniendo en juego no sólo regímenes de signos distintos, sino también estatutos de estados de cosas.» (Deleuze, Guattari, 1988, pág.13). Deleuze y Guattari caracterizan lo rizomático a partir del principio de conexión y heterogeneidad, de la multiplicidad, y del principio de ruptura 
asignificante, aspectos que pueden reconocerse de forma articulada en la poética teatral gestada por Pavlovsky.

Fiel a los saberes adquiridos en su formación y en su práctica como psicoanalista, Pavlovsky reconoce la necesidad del despliegue de la lógica inconsciente en el proceso de creación dramática. Tal como señala Geirola (2008), este elemento revela el legado de la producción teatral del actor y dramaturgo con la práctica psicoanalítica. Sin embargo, el concepto de inconsciente puesto en juego en la estética de la multiplicidad -y que será clave también a la hora de pensar sus abordajes en la práctica del psicodrama- se construye también a partir de una premisa deleuziana, que cuestiona su comprensión del inconsciente en términos representativos:

El gran descubrimiento del psicoanálisis fue el de la producción deseante, de las producciones del inconsciente. Sin embargo, con Edipo, este descubrimiento fue encubierto rápidamente por un nuevo idealismo: el inconsciente como fábrica fue sustituido por un teatro antiguo; las unidades de producción del inconsciente fueron sustituidas por la representación; el inconsciente productivo fue sustituido por un inconsciente que tan sólo podía expresarse (el mito, la tragedia, el sueño...) (Deleuze, Guattari, 1985, pág. 31).

Independientemente de las premisas que definen la lógica inconsciente dispuesta en el proceso creativo del actor, la poética de actuación del teatro de estados desestabiliza el principio de identidad que caracteriza la concepción del personaje stanislavskiano-strasbergiano. La noción de personaje, en tanto entidad psicológica estable, es puesta en crisis en sus principios fundamentales: la identidad, la conciencia y el principio de no contradicción. Estos aspectos son trascendidos por las fuerzas expresivas singulares que el actor imprime en la escena, en pos de generar nuevos sentidos y multiplicar los discursos contenidos en el texto: «en mi teatro la identidad del personaje se va alterando en diferentes estados, al punto que llega un momento en que el discurso que dice el personaje no corresponde a su identidad inicial» (Pavlovsky, 2001, pág. 213).

Tal como lo identifica Natacha Koss (2008), el teatro de estados configura también una metodología de trabajo. Uno de los aspectos centrales de este método implica reconocer lo que el propio Pavlovsky identificó en un principio como el coágulo, siguiendo la terminología utilizada por 
el escritor Julio Cortázar. Según lo explicita el escritor argentino en su novela 62/Modelo para armar, el coágulo es una imagen que refiere al acto de narrar cuando todo lo que se va a escribir se aglutina para formar parte de «un repentino bloque vertiginoso» (2004, pág. 14). El coágulo tiene un carácter informe y poco predecible. En la reflexión sobre sus procesos de creación, Pavlovsky se hace eco de las premisas cortazarianas y posteriormente las asimila al concepto de accidente, según las apreciaciones desarrolladas por Francis Bacon:

el otro día estaba pintando la cabeza de una persona, y lo que formaba la cuenca de los ojos, la naríz, la boca, era, cuando lo analizaba, solo un conjunto de formas que nada tenían que ver con ojos, nariz o boca, pero la combinación entre los contornos de la imagen reflejaba un parecido con la persona que yo estaba intentando pintar (...) esta imagen es una especie de paseo por la cuerda floja entre lo que se llama pintura figurativa y lo que se llama abstracción. Puede partir directamente de la abstracción, pero en realidad nada tendrá que ver con ella (Bacon en Sylvester, 2009, pág. 11).

La condición propia del accỉente funda para Pavlovsky una política de producción basada en el principio de infrasciencia, del desconocimiento respecto de la construcción que asumirá la forma escénica final.

Desde la perspectiva de la teoría de la formatividad desarrollada por Luigi Pareyson (1987), la operación poiética dispuesta en las formas de producción del teatro de estados pone el acento en la comprensión de la obra teatral en tanto forma formante, al considerar que el propio cuerpo del actor dispuesto en la escena construye progresivamente un modo de hacer. La producción escénica se construye a partir de un intentar, de un sistema de procedimientos desarrollados por medio de un conjunto de esbozos:

El descubrimiento surge sólo a través de los ensayos, y la obra acabada es una maduración que presupone un proceso de germinación e incubación a través del cual, mediante una coordinada sucesión de rectificaciones, correcciones, reinicios, selecciones, tachaduras, rechazos y sustituciones, la obra se define mientras se va decantando (pág. 111). 
Pavlovsky identifica los primeros atisbos del concepto del teatro de estados en el proceso de composición de la obra Telarañas. En ella «aparecen personajes que no se definen por la formación de su silueta psicológica sino que crecen y se desarrollan sólo en la «acción dramática (...) Los personajes de Telarañas son más bien voces, cuerpos en estados de afección (Pavlovsky, 2001, pág. 75).

En los rasgos que Pavlovsky perfila en torno a sus nuevas formas de trabajo se advierten las características iniciales que definen al modelo del teatro de cestados: se trata de una poética que nace de la pura intuición del actor -de su campo imaginario y asociativo- puesta en movimiento, que privilegia los caminos delineados por el azar en las formas de producción; una metodología de la prueba constante, del error, de la reescritura, de lo que se recoge en el estallido insólito que funda el accidente.

\section{CONTINUIDAD Y RESONANCIAS}

Un segundo eslabón en el desarrollo de la poética del teatro de estados se reconoce en el trabajo de Alberto Ure, director argentino con el cual Pavlovsky trabajó en las puestas en escena de Atendiendo al señor Sloane y Telarañas. Ure es un creador insoslayable a la hora de considerar el desarrollo del teatro de Buenos Aires a partir de la década del '60, y adquiere aún mayor relevancia cuando se contemplan sus reflexiones teóricas en torno a la dirección escénica y su vínculo con la actuación. Su mirada novedosa y una lucidez inusitada articulan una comprensión de la práctica actoral a partir de la reflexión sobre la naturaleza de los procesos creativos de los actores, la interacción que tejen en el trabajo con la dirección y, en particular, del lugar que ocupan en el imaginario social. Al igual que Pavlovsky, los hallazgos teóricos de Ure son consecuencia de una relectura y una apropiación crítica de los postulados de Jerzy Grotowski y Vsévolod Meyerhold; a ello se le suma el enorme impacto que tuvo para el director argentino el encuentro con el Open Theatre, el pensamiento teatral de Joseph Chaikin y los espectáculos de Enrique Vargas junto al grupo teatral Third World Revelationists, durante un viaje que Ure realizó a los Estados Unidos en 1969.

Para Ure, la actuación es un dispositivo catalizador de la memoria del cuerpo social, un archivo humano de los gestos y las modalidades expresivas del pasado: «Yo me puedo imaginar a actores que nunca vi, 
porque me acuerdo, o me imagino que me acuerdo, de mi padre y de sus gestos, $y$ en sus tonos, que siguen hablando dentro de mi, se refractan las actuaciones que lo conmovían» (2012, pág.22). Hay un mecanismo de circulación de las representaciones colectivas del pasado que operan en la práctica actoral y que se transmiten de generación en generación. A la vez, el ejercicio de la actuación materializa la posibilidad de fundar un yo «absoluto» $\mathrm{y}$ «totalitario», en donde «cada actor es una estrella, porque en el mundo de la actuación un personaje puede ser el centro del mundo, que es un sueño irresistible» (ibid, pág. 21).

Ure profundiza en sus reflexiones en torno al oficio actoral sobre un aspecto central que caracteriza al teatro de estados y que refiere a la relación entre el actor y su personaje, al afirmar que «el actor construye su personaje como una red de relaciones con su propia personalidad y con la misma construcción de otros actores, con la unión imaginaria que tiene con el director y con lo que supone apreciará el público» (pág. 11). Desde esta perspectiva, la categoría de personaje no es solamente un artificio construido por la literatura dramática; por el contrario, «cada actor tiene varios personajes íntegramente dibujados a la espera de una obra que los exprese y que, por pudor o excesivo amor, es lo que menos utiliza» (pág. 11).

A su vez, las reflexiones del director manifiestan una inquietud que será compartida e investigada de forma minuciosa por Ricardo Bartis: se trata de revisitar los métodos y los principios formales que definen al actor popular rioplatense. En la recuperación de los procedimientos y en la técnica que se advierte en este tipo de actores se reconocen las semillas de un modelo de actuación capaz de confrontar con las pedagogías stanislavskianas. Ure considera que la herencia del actor argentino frente a su pasado ha sido fracturada y gran parte de su obra teórica manifiesta una enfática reivindicación de algunos de los grandes cómicos populares argentinos, tales como Nini Marshall, Luis Sandrini, Alberto Olmedo o Jorge Luz. Tal como lo advierte Karina Mauro (2011) tanto en la producción escénica como en su reflexión teórica Ure «logra instalar a la mezcla o hibridación (de lo alto y lo bajo, lo culto y lo popular, lo nacional y lo extranjero), como una categoría estética válida y singular dentro de nuestro campo teatral» (pág. 362). Mauro también destaca el trabajo desarrollado por Oscar Ferrigno a partir de la década del ‘50 -una referencia que también está presente en la producción de $\mathrm{Pa}$ vlovsky- y el espectáculo Porca Miseria, dirigido por Lorenzo Quinteros 
en 1975, como antecedentes de la revaloración de los procedimientos formales del actor popular que Ure recupera en su producción. Para Mauro, en la propuesta estética de Ure «la Actuación popular será formalmente considerada por las características específicas que la diferencian de otras poéticas y metodologías, por lo que sus procedimientos serán aislados y susceptibles de ser incorporados por nuevos actores» (2011, pág. 376).

Las características que asume el concepto de teatro de estados en el trabajo de Ure, a su vez, marcan una diferencia central con los procesos creativos desarrollados por Pavlovsky: este último, de acuerdo a su doble condición de dramaturgo y actor, parte de la improvisación actoral y de la escritura escénica para conformar un texto dramático específico, correlato del trabajo desplegado sobre la escena. Ure, en cambio, propone un modelo de escritura escénica que parte del trabajo sobre textos dramáticos preexistentes. Las operaciones de selección y de puesta en escena ejecutadas por el director permiten reconocer también una política de dirección orientada hacia la relectura contemporánea de grandes clásicos de la literatura dramática universal: así se reconoce en sus propuestas escénicas de autores como Strindberg, Sófocles, Moliére o Shakespeare. El vínculo que la dirección de Ure mantiene con estos textos no tiene una pretensión representativa o ilustrativa. Por el contrario, para el director el universo ficcional delineado por el texto y el imaginario que la escena construye poseen una vida autónoma y diversa. Por el contrario, para el director el universo ficcional delineado por el texto y el imaginario que la escena construye poseen una vida autónoma y diversa y se manifiesta, según su propia definición, a partir de Jos vertientes:

«En la primera asoman las escenas que yo pondría en escena y, en la segunda, los textos que existen. Es azaroso que se encuentren pero, de alguna manera, a veces no feliz y a veces muy feliz, se tienen que encontrar. Lo que es seguro es que no se van a encontrar de una manera tal que las escenas ilustren las palabras. Es muy probable que exista una contradicción entre escenas y texto. Esto, en mí, es puramente inductivo, no es deliberado; me sale así y no he podido evitarlo» (Ure en Tcherkaski, 2016, pág.18) 
Un último aspecto central, dispuesto a modelar muchas de las premisas que caracterizan la política estética que caracteriza al teatro de estados, se expresa en el pensamiento de Ure a partir del reconocimiento de los fenómenos de transteatralización, de expansión de los procedimientos y las formas teatrales por afuera de los marcos convencionales e institucionalizados. En sus escritos teóricos, el director observa tempranamente de qué manera la esfera pública se apropia de los recursos escénicos y desdibuja las fronteras entre la realidad y la metáfora teatral. En Teatro y política: sacate la máscara, un texto escrito en 1987, el director afirma que el teatro ha sido «chupado» por la política:

Hoy parece lógico que Ronald Reagan haga de presidente de los Estados Unidos, y hasta que se sugiera la precandidatura de Yves Montand en la socialdemocracia francesa. Pero aquí estos ejemplos parecen obvios y tardíos: después de Eva Duarte de Perón, son muchas las actrices argentinas que adivinan la política como lógica culminación de su vocación inicial. Y no es por ambición personal, sino por una lógica casi cómica. (2003, pág. 39).

De la misma manera que, a partir de la Revolución Rusa, las demandas y las referencias de la política se introducen de forma explícita en el teatro y en el cine, Ure reconoce su presente como el tiempo de una progresiva apropiación de la actividad política de las operaciones y los procedimientos del espectáculo, en donde las técnicas y el oficio del actor adquieren una relevancia singular. A la vez, la práctica escénica revela una función clave que expresa formas diversas de problematizar el ejercicio del poder, las relaciones sociales y las lógicas que rigen la organización del bien común. El teatro configura un «laboratorio experimental de conductas y situaciones, donde se especula con modelos» (pág. 40). De allí que su gran poder no resida solamente en la proliferación de saberes ya conocidos o aceptados socialmente, sino sobre todo en su capacidad para construir hipótesis acerca de lo socialmente posible.

A partir del estreno de Potestad, en 1987, el concepto de teatro de estados se diversifica, permitiéndole a Pavlovsky dar cuenta no solo de su trabajo sino también de la producción escénica de otro conjunto de directores del período, entre los cuales se incluyen el propio Ure y en particular el trabajo escénico desarrollado por el actor y director Ricardo Bartis. 
En un artículo publicado en la revista «El Ojo-Mocho», Pavlovsky afirmaba:

Alguna vez dije que si Fernandes es el director del tradicional teatro representativo, Bartis es el director de los devenires dramáticos - del teatro de estados donde los actores experimentan con el texto-, desviando la historia y extraviando el tiempo cronológico por tiempo de intensidades. Nuevos ritornellos creados en el espectáculo Nuevos espacios tiempo. Espacios pre-extensivos. Los actores de los espectáculos de Bartis (Telarañas, Hamlet, Faciales argentinas, El corte) con poco recorrido tienen grandes diferencias de estados (Pavlovsky en Bartis, pág. 122).

En el teatro de Bartis, las concepciones y el aparato procedimental desarrollado por Pavlovsky y Ure se amplía y complejiza. Las ideas de primero, en torno a los procesos de construcción basados en la improvisación, la prueba directa de los actores sobre el espacio y los procesos de escritura escénica se manifiestan desde sus primeras producciones teatrales. Bartis insiste en la necesidad de pensar un teatro basado en el actor, que trascienda las demandas que los modelos representativos le han delegado históricamente. A diferencia de los principios stanislavskianos, donde el actor opera como un «intérprete» de las ideas expresadas por el autor del texto dramático, en el trabajo de Bartis es la propia dimensión expresiva y asociativa de la actuación la que confronta el sistema cerrado de significación sugerido por la literatura dramática y habilita nuevos sentidos posibles. De esta manera, el actor no debe someterse a la idea previa contenida en el texto dramático sino trascenderlo, aportando nuevas ideas y un campo de opinión específico, que nace de su propia intervención. A partir del desarrollo y la puesta en funcionamiento de sus fuerzas poéticas singulares, el actor trasciende la noción de "personaje», en tanto modelo compositivo construido en el plano textual.

La poética teatral de Bartis, al igual que los trabajos de investigación gestados en el marco de sus talleres de entrenamiento actoral, han sido centrales también para pensar la renovación de la dramaturgia en Buenos Aires a partir de la década del noventa.

A la manera del «desenmascaramiento» descrito por Pavlovsky, Bartis reconoce en la actuación un principio de desintegración de la 
identidad social e individual, junto a la configuración de una temporalidad extracotidiana:

El pensamiento teatral que viene de la actuación tiene que ver más con el instante, con que no hay nada previo a la existencia del cuerpo del actor, que funda un instante privilegiado y único. En realidad se va al teatro, no tanto a que le cuenten una historia, sino a ver actuar. Esto es, a ver un procedimiento, por un lado muy simple, pero por otro lado muy complejo, donde alguien muy parecido a nosotros, durante un tiempo se ausenta y produce otra temporalidad (Bartis, 2003, pág. 68).

La afirmación de ese instante privilegiado y único puede comprenderse como el territorio específico en el cual se manifiesta el principio de liminalidad en el teatro de estados, a partir de la puesta en tensión entre campos ontológicos diversos: cuerpo natural/cuerpo poético, representación/no-representación, dramático/no-dramático.

\section{TEATRO DE ESTADOS Y LIMINALIDAD}

Actor y acontecimiento son los elementos centrales desde los cuales la Filosofía del Teatro concibe una teoría de la actuación. A través de las acciones corporales, gestuales, físicas y físico-verbales, de su trabajo territorial y situado, en coordenadas espaciales y temporales concretas e irrepetibles, el actor genera la poíesis teatral y se ubica en el centro del acontecimiento escénico. El origen de este principio se halla en la premisas que definen el trabajo del director y teórico Jerzi Grotowski: el cuerpo del actor es el «núcleo sustantivo», insoslayable, no sustraíble del acontecimiento para producir la poíesis teatral (Dubatti, 2010). Reconocer la singularidad específica que formula en tanto poética de actuación el teatro de estados supone observar en él no sólo los caracteres distintivos que dan cuenta de una técnica y un modo de producción, sino también el conjunto de procedimientos que se articulan y jerarquizan sobre el cuerpo del actor como soporte. Tal como afirmamos anteriormente, la teoría del teatro de estados cuestiona un modelo de actor asentado en un principio representativo, y concibe la actuación en tanto entidad poética que trasciende el principio de contigüidad con la realidad, al afirmarse en su propia condición autónoma. En su propio movimiento y en el sistema de operaciones escénicas y formales que desarrolla, el teatro 
de estados pone de manifiesto su condición liminal, de tensión de campos ontológicos diversos en el acontecimiento teatral (Dubatti, 2016, pág. 8), donde las fronteras entre el arte y la vida, la ficción y la no-ficción, el cuerpo natural-social y el cuerpo poético, la representación y la norepresentación se difuminan y problematizan. Desde una perspectiva más general y abarcadora el teatro de estados pone en tensión de manera ostensible el carácter propiamente dramático del acontecimiento teatral y su reverso: la suspensión de toda dramaticidad.

Observemos con mayor detenimiento cada uno de los pares enunciados: en primer lugar, el actor en instancia de producción de poíesios tensiona la realidad cotidiana y el ente poético, a partir de la diferenciación de tres órdenes expresados en su propio cuerpo: el cuerpo natural-social del actor deviene en cuerpo poético, integrándose a la nueva forma, pero también el ejercicio de expectación reconoce en el cuerpo del actor un cuerpo modificado por el trabajo y la generación del cuerpo poético, es decir, un cuerpo afectado o en estado poético. El cuerpo poético permite a la vez distinguir en su espesor dos dimensiones, una pre-semiótica (fundamento del acontecimiento y volumen incapturable en términos sígnicos como totalidad) y una semiótica, en la que se reconocen a la vez tres instancias: el cuerpo semiótico 1 , signo de cuerpo poético que manifiesta su presencia en tanto acontecimiento en sí; cuerpo semiótico 2 , signo de universo referencial o signo de otro en sí, aquellos que fundan, nombran y describen un mundo de representación y sentido (universo referencial); cuerpo semiótico 3 , definido por un tercer estadio del signo, en el cual la estructura de ambos estadíos anteriores habilita una semiosis ilimitada, a partir de la interpretación de los signos del universo referencial (Dubatti, 2010, págs. 81-82). Cada poética en particular articula y define diversos grados de relevancia entre las dimensiones que conforman el cuerpo poético. El modelo de actor que define el teatro de estados torna ostensible la constitución del actor en tanto cuerpo afectado por intensidades y energías, conformando un salto o pasaje entre el universo referencial (el cuerpo del actor en tanto productor de signos que fundan, nombran y describen un mundo de representación y sentido) y el cuerpo del actor como signo de sí mismo, signo de la presencia poética (Cuerpo semiótico 1). La remisión al orden convivial y al carácter performativo del actor en fricción con el orden metafórico permite leer al teatro de estados como una práctica liminal, en tanto tensiona la relación establecida entre el cuerpo natural-social y el cuerpo poético. A su vez, la 
operación físico-expresiva ejecutada por el actor en el modelo del teatro de estados instituye un fenómeno fronterizo entre ficción y no ficción, al reconocer una poética específica que opera en las particularidades expresivas del actor por afuera de los límites del personaje (su personali$\partial a \partial$ ), de la estructura normativa del texto y de la lógica del espectáculo en el que la actuación se inscribe. Ricardo Bartis lo explicita de forma inmejorable, a partir del principio de violencia que articula la relación entre texto y escena:

Hay una violencia enorme entre la represión que ejerce el texto y el cuerpo asociativo de la actuación que es un devenir más libre, más «psicótico», más de mescolanza, de combinaciones azarosas, de devenires absolutamente casuales sin ninguna otra legislación o medida que el grado de afirmación que ese mismo discurso de actuación tiene. Por decirlo de manera ingenua: el estilo es el campo afirmativo. No hay otro estilo que la convicción: la actuación, en el momento de desarrollar el flujo tiene que tener un convencimiento autónomo de la relación que establece con el texto (...) Porque la relación con el texto es una relación racional: aunque sea poética, es racional. La relación con el punto de vista o el espectador, en cambio, es pura pulsión, pura intuición (Bartis, 2018).

\section{VARIACIONES MEYERHOLD}

Del conjunto de la producción escénica desarrollada por Eduardo Pavlovsky, Variaciones Meyerhold es la obra en la que los principios de la estética de la multiplicidad y del teatro de estados se manifiestan con mayor radicalidad. Estrenada en el 2005, la obra no solo recupera en su relato el legado de la actividad política y estética desarrollada por el director ruso, sino que permite reconocer en su figura otro de los grandes antecedentes en torno a los principios que definen el teatro de estados. Afirma Pavlovsky: «Nunca lo pensé, pero evidentemente Meyerhold me afecta profundamente hoy, no por sus deslumbrantes dispositivos escénicos sino por su concepto del trabajo sobre el cuerpo del actor» (Pavlovsky en Dubatti, 2005, pág. 60). Variaciones Meyerhold articula así una reflexión sobre la propia práctica escénica. 
El nacimiento de la obra se remonta a una serie de conversaciones que el propio Pavlovsky lleva adelante con su colega Hernán Kesselman. A partir de estas charlas y del conjunto de imágenes generadoras que Pavlovsky describe, la obra comienza a configurarse desde la lógica del «accidente»: la primer referencia sobre la que trabaja Pavlovsky es la imagen de del papa Juan Pablo II (Karol Wojtyla) y el impacto que le al actor $y$ director produjo la forma en que el parkinson afectaba los último días del papa polaco:

Yo trataba de mostrarle a Hernán que la imágen que se me estaba imponiendo era la imagen surgida de la voz de este pobre hombre que trataba desesperadamente de hablar y se cansaba al hacerlo. Hernán sobre esa imagen me introdujo otra imagen de él: me dijo que él veía al papa polaco y a mismo tiempo veía una imagen de un abuelo mío que estuviera hablando con él -un abuelo mío escritor y que yo le había dado los libros a Hernán (Pavlovsky, 2006, pág. 15).

Poco a poco, las diversas identidades adjudicadas a esa imagen doliente comienzan a confluir en Meyerhold y en la hipotética recreación de sus últimos días en el calabozo al que fue confinado por orden de Stalin, para ser torturado y finalmente asesinado en 1939.

Las variaciones ejecutadas por Pavlovsky en torno a la figura de $\mathrm{Me}-$ yerhold se presentan a la manera de un teatro borrador, una serie de laboratorios escénicos desarrollados desde el año 2004 en diversos espacios culturales, acompañados de una charla posterior por parte del teatrista. El trabajo presentado prescindió de un texto dramático escrito a priori; Pavlovsky eligió elaborar un recorrido por diversos acontecimientos en la vida y el pensamiento de Meyerhold, pero cada representación fue sometida a un ejercicio de improvisación que nacía del contacto con la materialidad de la escena y del encuentro con los espectadores. Desde la perspectiva de Pavlovsky, esta operación creativa configuró la ficción escénica en torno a Meyerhold como un ritornello melódico que respondía en cada función a los estímulos recibidos corporalmente. A su vez, las presentaciones partieron de una absoluta prescindencia de elementos escenográficos o de recursos técnicos, dejando al desnudo la propia corporalidad de Pavlovsky y su encuentro cara a cara con los espectadores. En la estela grotowskiana, Pavlovsky afirmó en Variaciones Meyerhold la construcción de un teatro «sin cleptomanías». 
La remisión al orden convivial y al principio de liminalidad se advierte en los propios procedimientos constructivos de la obra: la frontera entre el discurso del Meyerhold-personaje y del propio Pavlovsky se torna difusa, en tanto el régimen expresivo dispuesto por el actor para caracterizar al director ruso se nutre de su propia poética personal, del sistema de velocidades, energías ritmos y temperaturas que definen su forma de estar en la escena. De forma más explícita y evidente, el salto hacia el orden convivial, por fuera de los límites del personaje y del universo referencial al que pertenece, se manifiesta en los momentos en los cuales Pavlovsky interpela de forma directa al público. Variaciones Meyerhold se sustrae de la obligación representativa de la figura de Meyerhold para poner en tensión el orden ficcional con el tiempo presente de la escena, al tornar ostensible el cuerpo de Pavlovsky-actor como signo de la presencia poética, como cuerpo afectado, arrojado a trascender los límites del personaje en pos de la afirmación de su propia singularidad. Esta operación, a propósito del teatro de estados y de la multiplicación dramática es caracterizada por Pavlovsky (2006) a partir del verbo «dessujetizar». Se trata de reconocer en la práctica de la actuación la posibilidad de fundar un territorio «Por fuera de la representación. Por fuera de la silueta del personaje - intentando desbloquear sus intensidades. Potenciando al máximo sus devenires. Sus estados.» (pág. 17)

\section{Conclusiones}

La producción teatral y teórica llevada adelante por Pavlovsky, Ure y Bartis permiten reconocer la emergencia y el desarrollo de una metodología de creación escénica singular, que pone el acento en la potencia expresiva del actor como principio organizativo de la experiencia teatral. El teatro de estados, con sus diversos matices y variantes, manifiesta una política de producción que recoge una pluralidad de aportes prácticos y teóricos, entre los cuales se observan un principio de creación basado en la improvisación y en la intuición pura del actor —asentada en su campo imaginario y asociativo-, la reivindicación de los modelos de actuación popular criolla, y el reconocimiento de la ambivalente relación que la experiencia teatral mantiene con la esfera de lo real a partir de su propia naturaleza liminal. El azar como metodología y la apertura hacia lo insólito constituyen otra de las líneas propositivas que definen 
la comprensión del acontecimiento escénico desde la mirada del teatro de estados. A su vez, la indagación sobre las posibilidades expresivas que pone en juego el cuerpo del actor permite delinear una poética que violenta cualquier voluntad ilustrativa de la escena, cuestionando de forma radical la ilusión referencial de los modelos stanislavskianos y su concepción del trabajo del actor. Este conjunto de premisas creativas ha dado lugar a una multiplicidad de poéticas, y constituye uno de los aportes más destacables al desarrollo del teatro de Buenos Aires de las últimas décadas. Si bien no fueron abordados en este artículo, podemos considerar que la producción de grandes referentes como Pompeyo Audivert, Cristina Banegas, Sergio Boris, Federico León, Analía Couceyro, Bernardo Cappa o Eugenio Soto revelan de forma variable y diversa los ecos y los legados que guían esta modalidad de trabajo. Por lo tanto, tal como lo identificamos en la introducción, pensar el teatro de estados no supone concebir un entramado homogéneo de procedimientos y tópicos estables, sino más bien observar un sistema versátil de «principios que retornan» en la vibrante densidad de la producción teatral argentina.

\section{OBRAs CITADAS}

Artaud, A. (1987). El teatro y su Joble. Buenos Aires: Edhasa. Bartis, R. (2003). Cancha con niebla. Buenos Aires: Atuel. (2018, diciembre). Violencia y lenguaje: el teatro como ilusión social del Estado. La llave universal. Recuperado de: http://www. llaveuniversal.com

Cortazar, Julio (2004). 62/Modelo para armar. Suma de Letras: Madrid. Deleuze, G., Guattari, F. (1985). El antiedipo. Capitalismo y esquizofrenia. Barcelona: Paidós.

(1988). Mil Mesetas. Capitalismo y esquizofrenia. Valencia: Pre-textos. Dubatti, J. (2004). El teatro de Eduardo Pavlovsky. Poéticas y política. Vol. II. Tesis (inédita).

(2005). «Estudio preliminar: «Variaciones Meyerhold y el teatro micropolítico de la resistencia». En Pavolvsky E., Teatro completo 5. Buenos Aires: Atuel.

(2010). Filosofía del Teatro II. Cuerpo poético y función ontológica. Buenos Aires: Atuel. 
Geirola G. (2008, diciembre). «Antecedentes psicoanalíticos de la nueva dramaturgia. Los textos clínicos de Eduardo Pavlovsky». Telón de Fondo (n $\left.{ }^{\circ} 8\right)$. Recuperado de: http://www.telondefondo. org/numeros-anteriores/numero8/articulo/157/antecedentespsicoanaliticos-de-la-nueva-dramaturgia-argentina-los-textosclinicos-de-eduardo-pavlovsky.html

Mauro, K. (2011). La Técnica De Actuación en Buenos Aires. Elementos para un Modelo de Análisis de la Actuación Teatral a partir del caso porteño. Tesis. Inédita.

Pareyson, L. (1987). Conversaciones de estética. Madrid: Visor.

Pavlovsky, E. (2001). La ética Jel cuerpo. Nuevas conversaciones con Jorge Dubatti. Buenos Aires: Atuel.

(1999). Micropolítica de la resistencia. Buenos Aires: Edueba. (2006). La multiplicación dramática. Buenos Aires: Atuel.

Sylvester, D. (2009). La brutalidad de los hechos: entrevistas con Francis Bacon. Barcelona: Ediciones Polígrafa.

Tcherkaski, O. (2016). Rebeldes exquisitos. Conversaciones con Alberto Ure, Griselda Gambaro y Cristina Banegas, Buenos Aires: Leviatán.

Ure, A. (2003). Sacate la careta. Ensayos sobre teatro, política y cultura. Buenos Aires: Biblioteca Nacional. (2009). Ponete el antifaz (escritos, Jichos y entrevistas). Buenos Aires: Instituto Nacional del Teatro. 